May 2018

\title{
Collaborative task-sharing to enhance the Point-Of- Care Ultrasound (POCUS) access among expectant women in Kenya: The role of midwife sonographers
}

Sudhir Vinayak

Aga Khan University, sudhir.vinayak@aku.edu

Sharon Brownie

Aga Khan University, sharon.brownie@aku.edu

Follow this and additional works at: https://ecommons.aku.edu/ eastafrica_fhs_mc_imaging_diagn_radiol

Part of the Nursing Commons, and the Radiology Commons

\section{Recommended Citation}

Vinayak, S., Brownie, S. (2018). Collaborative task-sharing to enhance the Point-Of-Care Ultrasound (POCUS) access among expectant women in Kenya: The role of midwife sonographers. Journal of Interprofessional Care.

Available at: https://ecommons.aku.edu/eastafrica_fhs_mc_imaging_diagn_radiol/26 


\section{Collaborative task-sharing to enhance the Point- Of-Care Ultrasound (POCUS) access among expectant women in Kenya: The role of midwife sonographers}

\section{Sudhir Vinayak \& Sharon Brownie}

To cite this article: Sudhir Vinayak \& Sharon Brownie (2018) Collaborative task-sharing to enhance the Point-Of-Care Ultrasound (POCUS) access among expectant women in Kenya: The role of midwife sonographers, Journal of Interprofessional Care, 32:5, 641-644, DOI: $\underline{10.1080 / 13561820.2018 .1470499}$

To link to this article: https://doi.org/10.1080/13561820.2018.1470499

Published online: 10 May 2018.

Submit your article to this journal

Џll Article views: 73

View Crossmark data ¿ 


\title{
Collaborative task-sharing to enhance the Point-Of-Care Ultrasound (POCUS) access among expectant women in Kenya: The role of midwife sonographers
}

\author{
Sudhir Vinayak and Sharon Brownie $\mathrm{e}^{\mathrm{b}, \mathrm{c}, \mathrm{d}}$ \\ aDepartment of Imaging \& Diagnostic Radiology, Aga Khan University Hospital, Nairobi, Kenya; ${ }^{b} S c h o o l$ of Nursing \& Midwifery, Aga Khan \\ University, Kenya, East Africa; 'School of Medicine, Griffith University, Australia; ${ }^{\mathrm{d} G r e e n ~ T e m p l e t o n ~ C o l l e g e, ~ O x f o r d ~ U n i v e r s i t y, ~ U K ~}$
}

\begin{abstract}
Unrealized maternal and child health goals continue to challenge Kenya where adverse outcomes remain high and diagnostic services are limited. The acute shortage of doctors and radiographers requires alternate human resources for health $(\mathrm{HRH})$ with the ability to identify risk factors in pregnancy through Point-Of-Care Ultrasound (POCUS). A specialist radiologist and ultrasonography team partnered with midwives to adopt interprofessional task sharing and capacity building. Faculty from the Radiology Department of our hospital designed and implemented the project which was carried out at three outreach health service centres. Designing and implementing a training model to skill midwife sonographers with the capacity to accurately identify risk factors in pregnancy is an effective model to increase POCUS access. A collaborative task sharing model focused on training quality, validation of results, tracking of errors and specialist level clinical supervision yielded a safe and scalable model of $\mathrm{HRH}$ capacity building. Programme evaluation, verification of outcomes and dissemination of results were all monitored. The project was a successful HRH task sharing and interprofessional learning initiative involving task sharing a clearly defined suite of sonographer competencies with participating midwives. The programme increased POCUS accessibility at the three outreach clinics with proven outcomes in the early detection and referral of risk factors in pregnancy.
\end{abstract}

ARTICLE HISTORY

Received 19 September 2017

Revised 14 February 2018

Accepted 25 April 2018

\section{KEYWORDS}

High risk pregnancy; Kenya; maternal health services; midwifery; POCUS; task sharing; ultrasonography

\section{Introduction}

Safe birth is the undisputed right of every childbearing woman and baby. Albeit global improvements in maternal child health $(\mathrm{MCH})$ statistics, Kenya's maternal mortality remains higher than both the global average and in comparison to a number of other lower-middle income nations (World Health Organization, 2016). Infant mortality rates are of equal concern with Kenya continuing to report rates higher than the global average (World Health Organization, 2016).

Kenya's unrealized MCH millennium goals now translate to ambitious sustainable development goals inclusive of aims to eliminate preventable death, reduce maternal mortality ratios and reduce neonatal mortality (The United Nations, 2015). Realization of these goals requires improved access to $\mathrm{MCH}$ and diagnostic services. Current estimates suggest that less than $5 \%$ of pregnant women have access to an ultrasound scan during pregnancy. Subsequently, significant numbers of undetected high-risk issues such as placenta praevia, fetal and/ or pelvic dystocia remain undetected and pose life-threatening risks to both mothers and babes (Yego, D'Este, Byles, Stewart Williams, \& Nyongesa, 2014). Reduced incidence of high-risk complications is dependent upon improved antenatal care and education including enhanced access to antenatal monitoring and diagnostic initiatives such as Point-Of-Care Ultrasound Services (POCUS) (Yego et al., 2014).

Unarguably, lives of mothers and babies are saved through improved access to antenatal care, skilled $\mathrm{HRH}$ resources including diagnostic services such as POCUS. However, workforce and service shortages persist with the widespread mismatch between where $\mathrm{MCH}$ services are needed and where specialist personnel are located (Global Health Workforce Alliance and World Health Organization, 2014). Further disparity exists due to socioeconomic and rural factors with POCUS primarily a privilege enjoyed by urban middle to upper-class women and unattainable by women in remote low-income geographies (Vinayak, Sande, Nisenbaum, \& Pállson Nolsøe, 2017).

\section{Background}

This HRH initiative involves a task sharing project enabling practising midwives to fill gaps arising from shortages of sonographers and to develop competencies as midwife sonographers. The initiative trained midwives to perform basic ultrasound aimed at identifying and referring risk factors in pregnancy. The primary focus was to enhance access to safe; quality confirmed POCUS, designed and delivered with the direct input of a specialist radiologist and ultrasonography team. The programme involved an interprofessional education initiative using concepts of teamwork and task sharing along with rigorously tested new technologies and teleradiology innovations (Vinayak et al., 2017).

The collaboration involved radiologists, midwives, and sonographers working together to fully understand their respective roles in rural versus base hospital locations. Mutual learning occurred as the midwives, sonographers, and radiologists gained

CONTACT Sudhir Vinayak sudhir.vinayak@aku.edu $\Theta$ Department of Imaging \& Diagnostic Radiology, Aga Khan University Hospital, 3rd Parklands Avenue, Nairobi, Kenya

(c) 2018 Aga Khan University Hospital, Nairobi 
Table 1. Considerations in task sharing and programme specific implementation (Patel, 2012, 2015).

SUNDAR (meaning 'attractive' in Hindi)

$\mathrm{S}$ Simplify messages and terms and express concepts in simple terms that can be understood by all

UN Unpack complex healthcare interventions to pieces that can be shared and taught to others

D Deliver close to people and the community to enhance health service access

A Use affordable and available human resources to deliver care

$\mathrm{R} \quad$ Reallocate and refocus effort of specialists to collaborative interprofessional and community engagement

Application in the Development of POCUS

$\mathrm{S}$ Commence discussions with both midwives and community stakeholders avoiding the use of profession-specific sonography terminologies

UN Identify sonography competencies and tasks which can be shared and taught to the health professionals most aligned with the delivery of $\mathrm{MCH}$ services, specifically midwives

D Pilot delivery of POCUS in three locations without current service and over a range of distance from $20-400 \mathrm{~km}$ from our hospital

A Work with both urban and rurally-based midwives to address shortages in sonography personnel by increasing access to POCUS

$\mathrm{R}$ Expand the role of radiologists and sonographers to role of teacher, mentor, health workforce collaborator and expert advisor rather than a service delivery function alone

more insight into the routines and patterns of client presentations in rural outputs (Table 1). Unexpected insights were gained in respect to matters such as POCUS as a facilitator of increasing father's interest and involvement in pregnancy and the provision of evidence refuting currently reported literature asserting mothers in low and middle-income countries (LMICs)do not have accurate knowledge of their last menstrual period. These shared learnings provide an opportunity for further collaborative learning and research.

The concept of collaborative 'task shifting' is not new and its application in LMICs is now well-documented with proven evidence that, with quality training and supervision, many tasks can be safely performed by health workers with lower levels of qualification (e.g., Dawson, Buchan, Duffield, Homer, \& Wijewardena, 2014; McPake \& Mensah, 2008). The World Health Organization (2008) global guidelines on Task Shifting promote this as an approach by which health workforce gaps could be addressed and by which health workforces could be strengthened defining task shifting as the process by which "specific tasks are moved, where appropriate, from highly qualified health workers to health workers with shorter training and fewer qualifications" (p. 2). Importantly, the guidelines include information to ensure that the process of task shifting is both safe and effective. Safety guidelines include standardized training along with supportive supervision and assessment (World Health Organization, 2008).

The team involved in this project preferred a model of 'task sharing' as had been promoted in some other contexts rather than a 'shiff' of full POCUS responsibility (Olson, 2012). During planning, the team undertook an analysis of published task shifting and sharing implementation models and safety guidelines. They decided to employ the model developed Patel $(2012,2015)$, which contains the following key principles: ensuring initiatives are based on available best practice; systematically testing for viability and feedback; facilitating the input and engagement of diverse stakeholders; embedding the initiative in established health care services, preferably government services; and, ensuring rigorous evaluation; disseminating results; and finally, working with government to scale-up the initiative.

\section{Project methods}

Based on these principles, the project team adopted all components of quality POCUS and identified the essential requirements to safely deliver such services. First, midwives were identified as the optimal interprofessional colleagues with whom to partner due to their existing knowledge and experience in matters pertaining to the female reproductive system. Second, a detailed curriculum was developed to train sonography-naïve midwives to deliver POCUS and accurately identify high risk pregnancies.

Uniquely, the initiative then combined a tablet platform, mobile phone transmission and teleradiology to connect remotely with hospital-based specialists in a process of image and diagnostic verification (Vinayak et al., 2017). In line, with recommended best practice guidelines, the pilot initiative included continual verification of findings during continuous midwife to radiologist interprofessional exchange and further verification of findings through post-delivery follow-up and diagnostic confirmation.

The pilot initiative was carried out in three locations within Kenya which are service centres of the Aga Khan University Hospital Nairobi (AKUHN). Locations were chosen at Kiambu, Embu, and Malindi at 20,120 and 400 kilometers, respectively, from the main hospital setting. This enabled testing of the mobile and teleradiology innovations over a range of distances. Three midwives with no prior knowledge or experience in performing an ultrasound or reading and interpreting an image were selected from each of the pilot sites.

Core principles of measurement and evaluation were embedded into every aspect of this initiative with each assessment point fully recorded and evaluated regularly across the project (Vinayak et al., 2017). An element missing from the only other published POCUS pilot project in Kenya which subsequently reported a need for refresher training for a significant number of the unspecified health workers involved in the project (Bell, Wachira, \& Denning, 2016).

Ethical approval was sought from the Human Research Ethics Committee (HREC) at Aga Khan University, Nairobi (Ref: 2014/REC-58 v2) before the project commenced.

\section{Project outcomes}

The initiative aimed to deliver a high-quality POCUS with measurable changes in HRH capacity building and proven accuracy in the detection of high-risk pregnancies. Below we outline key project outcomes in the following three areas.

\section{Midwife sonography competency}

This component of the project focused on the following:

- Pre-training assessment: Midwives were enrolled in an on-line training programme in the basics of ultrasound specific to the pregnancy and childbirth accessible from each of the designated sites. A $100 \%$ pass-rate, in less than five attempts, was required in order for midwives to proceed with the training programme. Midwives passed on either the first or second attempt.

- In-training assessment: At the base hospital, midwives completed a four week training programme which 
involved a one hour morning class session from a qualified sonographer followed by six hours of hands-on training and a further one hour end of day period of feedback and further training. Midwives progressed from observation to fully measured competency over the four week period. Daily observation from the expert training sonographer documented increases and attainment of competencies along with reductions in time of scanning from 45 minutes to 20 minutes.

- End of training assessment \& evaluation: A formal assessment involving 'Direct Observational work in Practice skills' and a written exam was undertaken in week five following which the Midwife Sonographers were formally certified by the specialist radiologist. All midwives passed the final assessment on their first attempt.

- In-practice assessment \& evaluation: Rigorous processes of measurement and assessment continued after each trainee had returned to their home health service. Evaluation focused on the quality of ultrasound practice and associated innovations in teleradiology.

\section{Teleradiology innovations and performance}

Specialist IT training involved the development of competencies in the use of a tablet platform, connected care (CCC teleradiology) software, internet explorer browser, and mobile technologies. Evaluation included focus on clarity of images from different geographic locations, transmission times and IT functionality:

- Clarity of image: the quality of image and transmission times was consistent across the distances of 20,120 and 400 kilometers

- Transmission times: the average turn-around time for post scan validation was 12 minutes of which 4 minutes was required for transmission of scans to the base hospital

- Technological functioning: No problems were reported in respect to the mobile phone, modem or CCC system.

\section{Quality of ultrasound practice}

The study population included patients between the ages of 18-50 yrs who consented to undergo scanning at one of the three designated health facilities. Participants were informed that the primary purpose of the scanning was for gestational dating and to rule-out a high-risk pregnancy:

- Post delivery validation of results: 271 ultrasound scans were performed and 220 patients were able to be located for post-delivery follow-up. Post-delivery accuracy of scans performed by the midwives was $99.63 \%$. ${ }^{1}$

\section{Discussion}

Much has been written regarding the benefits of collaboration with task sharing between various health practitioners. Collaborative task sharing is highlighted as an activity whereby health service access can be extended to populations with effectiveness and sustainability. It also has the benefit of allowing practitioners to achieve together more than can be achieved as individuals for services over wider geographical areas and to larger populations (Babiker et al., 2014; Green \& Johnson, 2015). Saba and colleagues (2012), for example, assert that current models of effective primary health care delivery have required a move away from the historical model of lone physicians providing care to that of high performing healthcare teams. Factors such as increasing co-morbidities, complexity in care specialization, a global demand for quality patient care, and, contexts of workforce shortages have necessitated focus on patient-centred teamwork with task sharing across teams (Babiker et al., 2014; Dawson et al., 2014).

This HRH capacity building pilot demonstrates that collaborative interprofessional task sharing between, radiologists, sonographers and midwives is a viable solution to current HRH shortages in Sub-Saharan Africa and other LMIC settings. The interprofessional task sharing initiative provided a platform for the establishment of a collaborative model of care that effectively addressed geographical issues of health service access along with the provision links and pathways for referral for detected high-risk scenarios. Major change was identified in all services measured with progression from no existing POCUS service to good quality service at each of the three pilot sites. Documented guidelines in task sharing provide an important guide in ensuring 'safe practice' in expanding POCUS. Collaboration, innovation, education, and evaluation are central lessons to success in such endeavours. Lesson learned from the project confirm that collaborative, interprofessional task sharing between specialist radiologists, sonographers and midwives can be an effective model of increasing access to POCUS in underserviced areas. Further, building on the existing knowledge of midwives in matters pertaining to the female reproductive system, pregnancy and birth proved to be an effective platform from which to increase $\mathrm{HRH}$ capacity in the early and accurate identification of highrisk pregnancies. Innovations in teleradiology then expanded the ability to address current HRH shortages and provide high-quality POCUS. The model also demands a well-constructed competency-based training programme with continuous assessment and feedback as critical to positive outcomes. Importantly, the training programme should include pre-entry testing, supervised training in the base hospital with competency-sign off followed by ongoing collaborative exchange and specialist supervision of field-based practice. Immediate feedback on all transmitted images closes the quality loop. Development of online resources provides additional value. Finally, continual measurement and feedback loops and the formal end of training assessment and evaluation are critical for quality assurance and safe practice. Evaluation must include specialist validation of highrisk findings following each transmitted scan along with post-delivery confirmation of findings.

\section{Declaration of interest}

The authors report no competing interests. The authors alone are responsible for the writing and content of this article. 


\section{Funding}

Philips Medical Systems (Bothell, WA, USA) provided all the ultrasound machines, e-module, and trainers for the midwives. They fully funded this project hoping that it will be implemented in resource-poor areas. In addition, the authors would like to acknowledge the support and encouragement from the World Federation for Ultrasound in Medicine and Biology in the design and implementation of this project.

\section{References}

Babiker, A., El Husseini, M., Al Nemri, A., Al Frayh, A., Al Juryyan, N., Faki, M. O., ... Al Zamil, F. (2014). Health care professional development: Working as a team to improve patient care. Sudanese Journal of Paediatrics, 14(2), 9-16.

Bell, G., Wachira, B., \& Denning, G. (2016). A pilot training program for point-of-care ultrasound in Kenya. African Journal of Emergency Medicine, 6(3), 132-137. doi:10.1016/j.afjem.2016.03.002

Dawson, A. J., Buchan, J., Duffield, C., Homer, C. S. E., \& Wijewardena, K. (2014). Task shifting and sharing in maternal and reproductive health in low-income countries: A narrative synthesis of current evidence. Health Policy and Planning, 29(3), 396-408. doi:10.1093/ heapol/czt026

Global Health Workforce Alliance and World Health Organization. (2014). A universal truth: No health without a workforce. Retrieved from http://www.who.int/workforcealliance/knowledge/resources/ hrhreport2013/en/

Green, B. N., \& Johnson, C. D. (2015). Interprofessional collaboration in research, education, and clinical practice: Working together for a better future. Journal of Chiropractic Education (Allen Press Publishing Services Inc.), 29(1), 1-10.
McPake, B., \& Mensah, K. (2008). Task shifting in health care in resource-poor countries. Lancet, 372(9642), 870-871. doi:10.1016/ S0140-6736(08)61375-6

Olson, D. J. (2012). Task sharing, not task shifting: Team approach is best bet for HIV care. Retrieved from http://www.intrahealth.org/blog/task-sharingnot-task-shifting-team-approach-best-bet-hiv-care\#.WAw8D499600

Patel, V. (2012). Mental health for all by involving all. Retrieved from https://www.ted.com/talks/vikram_patel_mental_health_for_all_by_ involving_all

Patel, V. (2015). SUNDAR: Mental health for all by all. BJPysch International, 12(1), 21-23. doi:10.1192/S2056474000000118

Saba, G. W., Villela, T. J., Chen, E., Hammer, H., \& Bodenheimer, T. (2012). The Myth of the lone physician: Toward a collaborative alternative. The Annals of Family Medicine, 10(2), 169-173. doi:10.1370/afm.1353

The United Nations. (2015). Sustainable development goals. Retrieved from http://www.un.org/sustainabledevelopment/sustainable-develop ment-goals/

Vinayak, S., Sande, S., Nisenbaum, H., \& Pállson Nolsøe, C. (2017). Training midwives to perform basic Obstetric PoCUS in rural areas using a tablet platform and mobile phone transmission technology A WFUMB COE project. Ultrasound in Medicine \& Biology. doi:10.1016/j.ultrasmedbio.2017.05.024

World Health Organization. (2008). Task shifting: Rational redistribution of tasks among health workforce teams. Retrieved from http://www. who.int/healthsystems/TTR-TaskShifting.pdf?ua=1

World Health Organization. (2016). Health statistics 2016: Health situation analysis of the African region. Retrieved from https://www.aho. afro.who.int/sites/default/files/publications/5266/Atlas-2016-en.pdf

Yego, F., D’Este, C., Byles, J., Stewart Williams, J., \& Nyongesa, P. (2014). Risk factors for maternal mortality in a Tertiary Hospital in Kenya: A case control study. BMC Pregnancy and Childbirth, 14(38). doi:10.1186/1471-2393-14-38 